\title{
Erratum to: Caffeoylquinic Acid Derivatives Protect SH-SY5Y Neuroblastoma Cells from Hydrogen Peroxide-Induced Injury Through Modulating Oxidative Status
}

\author{
Xiao-Wen Jiang ${ }^{1,2} \cdot \mathrm{Jun}^{-P e n g} \mathrm{Bai}^{2} \cdot$ Qiao Zhang ${ }^{2}$ Xiao-Long $\mathrm{Hu}^{2}$ • \\ Xing Tian $^{2} \cdot$ Jun Zhu ${ }^{2} \cdot$ Jia Liu $^{2} \cdot$ Wei-Hong Meng' ${ }^{1}$ Qing-Chun Zhao ${ }^{1}$
}

Published online: 17 June 2016

(C) Springer Science+Business Media New York 2016

\section{Erratum to: Cell Mol Neurobiol \\ DOI 10.1007/s10571-016-0387-7}

The original version of this article unfortunately contained an error in Fig. 5. The corrected Fig. 5 is given below.

The online version of the original article can be found under doi:10.1007/s10571-016-0387-7.

\footnotetext{
Qing-Chun Zhao

zhaoqingchun1967@163.com

1 Department of Pharmacy, General Hospital of Shenyang Military Area Command, Shenyang 110840, China

2 Department of Traditional Chinese Medicine, Shenyang Pharmaceutical University, Shenyang 110016, China
} 

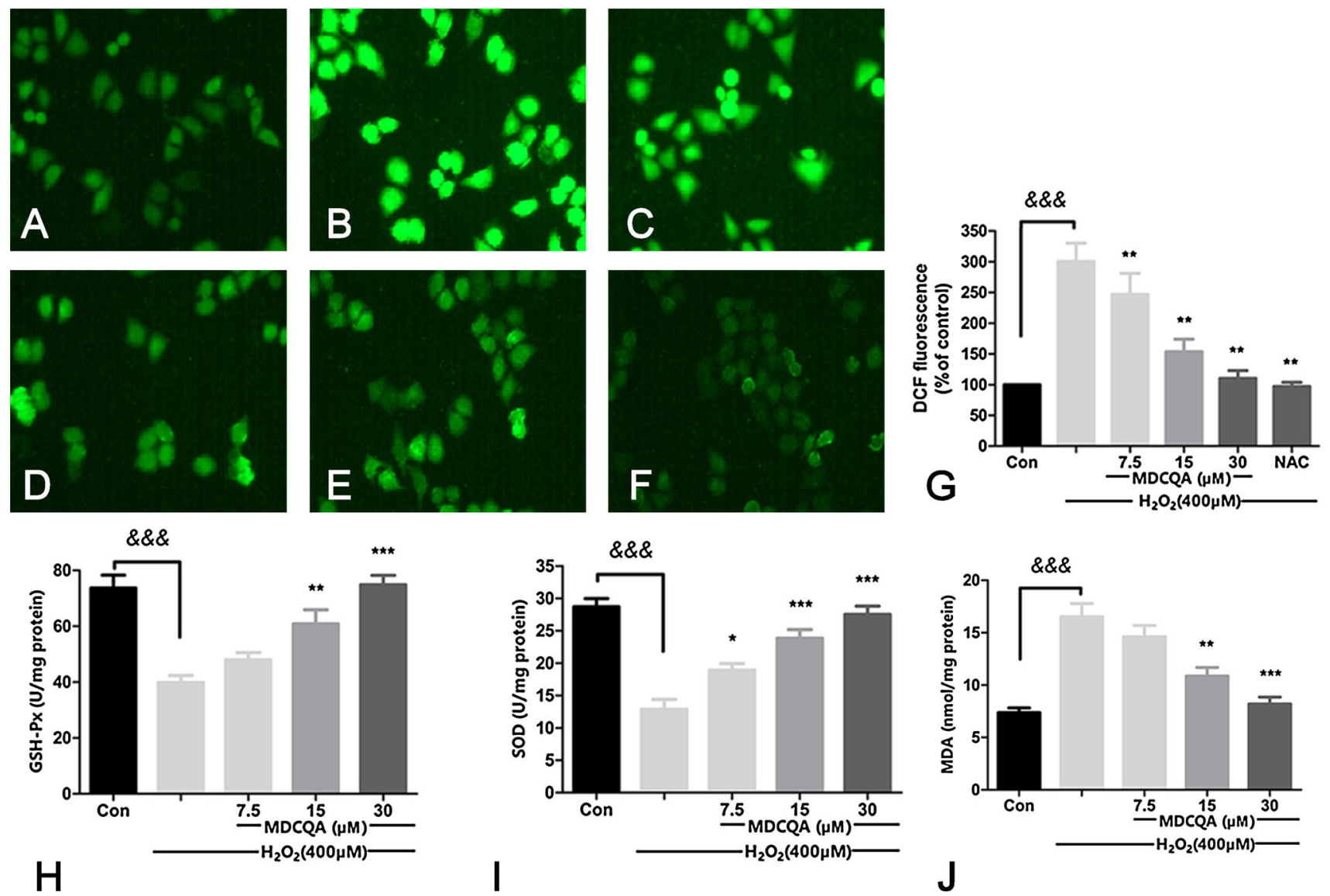

Fig. 5 Neuroprotection of MDCQA on attenuating ROS generation, the bar graphs showed the percentage of DCF fluorescence intensity. Effects of MDCQA on modulated levels of GSH-Px (h), SOD (i) and improved the GSH-Px and SOD activities, and decreased the MDA level in $\mathrm{SH}-\mathrm{SY} 5 \mathrm{Y}$ cells induced by $\mathrm{H}_{2} \mathrm{O}_{2}$. ROS production was assessed with DCFH-DA fluorescence dye (magnification $\times 400$ ). a Control; b $400 \mu \mathrm{M} \mathrm{H}_{2} \mathrm{O}_{2}$; c $400 \mu \mathrm{M} \mathrm{H}_{2} \mathrm{O}_{2}+7.5 \mu \mathrm{M}$ MDCQA; d $400 \mu \mathrm{M} \mathrm{H} \mathrm{H}_{2} \mathrm{O}_{2}+15 \mu \mathrm{M}$ MDCQA; e $400 \mu \mathrm{M} \mathrm{H} \mathrm{H}_{2} \mathrm{O}_{2}+30 \mu \mathrm{M}$ MDCQA; $\mathbf{f} 400 \mu \mathrm{M} \mathrm{H}_{2} \mathrm{O}_{2}+10 \mu \mathrm{M}$ NAC; $\mathbf{g}$ Quantitative analysis of MDA (j) in SH-SY5Y cells induced by $\mathrm{H}_{2} \mathrm{O}_{2}$. Data are showed as mean \pm S.E.M. $(n=3) .{ }^{\& \&} p<0.01$ and ${ }^{\& \& \&} p<0.001$ versus the control group; $* p<0.05$, ** $p<0.01$, and $* * * p<0.001$ versus the $\mathrm{H}_{2} \mathrm{O}_{2}$-treated group 